\title{
Photoacoustic imaging as a highly efficient and precise imaging strategy for the evaluation of brain diseases
}

\author{
Ting Qiu ${ }^{1}$, Yintao Lan ${ }^{1}$, Weijian Gao ${ }^{1}$, Mengyu Zhou ${ }^{1}$, Shiqi Liu ${ }^{2}$, Wenyan Huang ${ }^{2}$, Sujuan Zeng ${ }^{2}$, \\ Janak L. Pathak ${ }^{2}$, Bin Yang ${ }^{1}$, Jian Zhang ${ }^{1,2} \wedge$ \\ ${ }^{1}$ Department of Biomedical Engineering, School of Basic Medical Sciences, Guangzhou Medical University, Guangzhou, China; ${ }^{2}$ Affiliated \\ Stomatology Hospital of Guangzhou Medical University, Guangzhou Key Laboratory of Basic and Applied Research of Oral Regenerative Medicine, \\ Guangzhou, China
}

Correspondence to: Jian Zhang. Department of Biomedical Engineering, School of Basic Medical Sciences, Guangzhou Medical University, Guangzhou 511436, China. Email: jianzhang@gzhmu.edu.cn.

\begin{abstract}
Photoacoustic imaging (PAI) is an emerging imaging strategy with a unique combination of rich optical contrasts, high ultrasound spatial resolution, and deep penetration depth without ionizing radiation. Taking advantage of the features mentioned above, PAI has been widely applied to preclinical studies in diverse fields, such as vascular biology, cardiology, neurology, ophthalmology, dermatology, gastroenterology, and oncology. Among various biomedical applications, photoacoustic brain imaging has great importance due to the brain's complex anatomy and the variability of brain disease. In this review, we aimed to introduce a novel and effective imaging modality for diagnosing brain diseases. Firstly, a brief overview of two major types of PAI system was provided. Then, PAI's major preclinical applications in brain diseases were introduced, including early diagnosis of brain tumors, subtle changes in the chemotherapy response, epileptic activity and brain injury, foreign body, and brain plaque. Finally, a perspective of the remaining challenges of PAI was given for future advancements.
\end{abstract}

Keywords: Photoacoustic imaging; brain diseases; diagnosis; imaging modality

Submitted Jul 08, 2020. Accepted for publication Nov 17, 2020.

doi: 10.21037/qims-20-845

View this article at: http://dx.doi.org/10.21037/qims-20-845

\section{Introduction}

Photoacoustic imaging (PAI) is a promising optical imaging method that has been actively evaluated for translation from bench-to-bedside (1). In PAI, light pulses excite target subjects, cause thermal expansion, and then emit acoustic waves, which are recognized by ultrasound (US) transducer (2). The acquired signal can be recorded on the computer by converting US waves into electrical signals. Then, highresolution images can be reconstructed employing specific computer algorithms. The imaging capability of PAI is further enhanced by the availability of broad choices of contrast agents.

A wide variety of endogenous chromophores or exogenous contrast agents can be applied to PAI to comprehensively reflect physiological and pathological information and disease stage (3). Especially, endogenous chromophores including oxyhemoglobin $\left(\mathrm{HbO}_{2}\right)(4)$, deoxyhemoglobin $(\mathrm{Hb})(5-7)$, melanin (8), fat (9), water (10), and nucleic acids (11) possess different optical absorption, which enables PAI to capture subtle changes in the tissue micro-environment, such as angiogenesis in the tumor, lipid accumulation in atherosclerosis $(9,12,13)$, and melanin deposition in the skin (8). Also, the broad choice of

\footnotetext{
^ ORCID: 0000-0002-9665-9322.
} 
Table 1 Comparison between PAI and other imaging modalities in clinical application of brain diseases

\begin{tabular}{|c|c|c|c|c|c|c|}
\hline $\begin{array}{l}\text { Imaging } \\
\text { modality }\end{array}$ & Resolution & Speed & Penetration & Price & Safety & Main clinical application in brain disease \\
\hline US & $30-500 \mu \mathrm{m}$ & sec-min & $\mathrm{mm}-\mathrm{cm}$ & + & Safe & Vascular malformation, venous plaque \\
\hline MRI & $25-100 \mu \mathrm{m}$ & min-hour & No limit & +++ & $\begin{array}{l}\text { Strong magnetic } \\
\text { field }\end{array}$ & Brain atrophy, cerebral hemorrhage, cerebral infarction, tumor \\
\hline SPECT & $0.3-1 \mathrm{~mm}$ & sec-min & No limit & +++ & lonizing radiation & Epilepsy, migraine, Parkinson's disease, Alzheimer's disease \\
\hline PAl & $10-500 \mu \mathrm{m}$ & sec-min & $\mathrm{mm}-\mathrm{cm}$ & + & Safe & $\begin{array}{l}\text { Brain tumor, epilepsy, cerebrovascular disease, Amyloid } \\
\text { cerebrovascular disease }\end{array}$ \\
\hline
\end{tabular}

PAI, photoacoustic imaging; US, ultrasound; CT, computed tomography; MRI, magnetic resonance imaging; PET, positron emission tomography; SPECT, single photon emission computed tomography; FL, fluorescence imaging.

exogenous contrasts for PAI, including organic dyes (14-16), nanoparticles (17-21), and reporter genes (22-24), plays a unique and valuable role in the detection of various diseases.

Consequently, endogenous and exogenous agents are of great importance as a supplement of PAI. In comparison with other traditional biomedical imaging modalities, PAI possesses several unique advantages: (I) In contrast with $\mathrm{X}$-ray, computed tomography (CT), and positron emission tomography (PET), PAI does not employ ionizing radiation. (II) PAI has a superior spatial resolution in biological tissues compared to US imaging (25). (III) PAI requires less time for detection than magnetic resonance imaging (MRI). (IV) Compared with fluorescence imaging (FLI), PAI possesses better molecular sensitivity $(26,27)$. These unique advantages allow PAI to play an increasingly critical role in both preclinical research and promising clinical practice. Table 1 summarizes further specific differences between PAI and other imaging methods.

The brain is the most complex organ in the human body. It controls our feeling, action, memory, and thoughts. The forebrain, midbrain, and hindbrain are the three major divisions of the brain, and these structures have a multitude of functions. The forebrain is responsible for motor control, relaying sensory information, and controlling autonomic functions. The midbrain is involved in auditory and visual responses as well as motor functions. The hindbrain helps maintain balance, movement coordination, the conduction of sensory information, and control such autonomic functions as breathing, heart rate, and digestion. Brain disease tends to affect the functions of the human body severely.

Moreover, as the most sensitive and vital organ in the body, the brain is susceptible to any kind of infection and other disorders of varying intensity, such as traumatic brain injury, brain tumor, epilepsy, alcoholism, amnesia, altitude sickness, and autism, among others. Each of the abovementioned conditions adversely affects the functions of the brain. Therefore, it is a matter of urgency to develop a novel and efficient imaging approach superior to other imaging methods for the early diagnosis of brain diseases. This review focused on PAI as a robust research tool and medical method for diagnosing brain disease. The use of PA images can provide valuable information about brain diseases and enhance other mainstream imaging methods' findings. Further exploration may lead to the discovery of more useful applications for PAI in the biomedical field.

\section{Representative PAI systems}

For a better understanding of the PA devices, this section presents a brief overview of photoacoustic systems. There are two major types of PAI systems; one is based on photoacoustic microscopy (PAM), and the other is based on photoacoustic computed tomography (PACT). The PAM is designed for high-resolution $(1-50 \mu \mathrm{m})$ imaging over a shallow depth, while PACT is targeted at deeper imaging depth with a compromised spatial resolution $(50-200 \mu \mathrm{m})(25)$. Tissues at a depth of millimeters can be imaged using PAM with micrometer-scale resolution, whereas PACT can be used to image tissues at a depth of centimeters with 
A
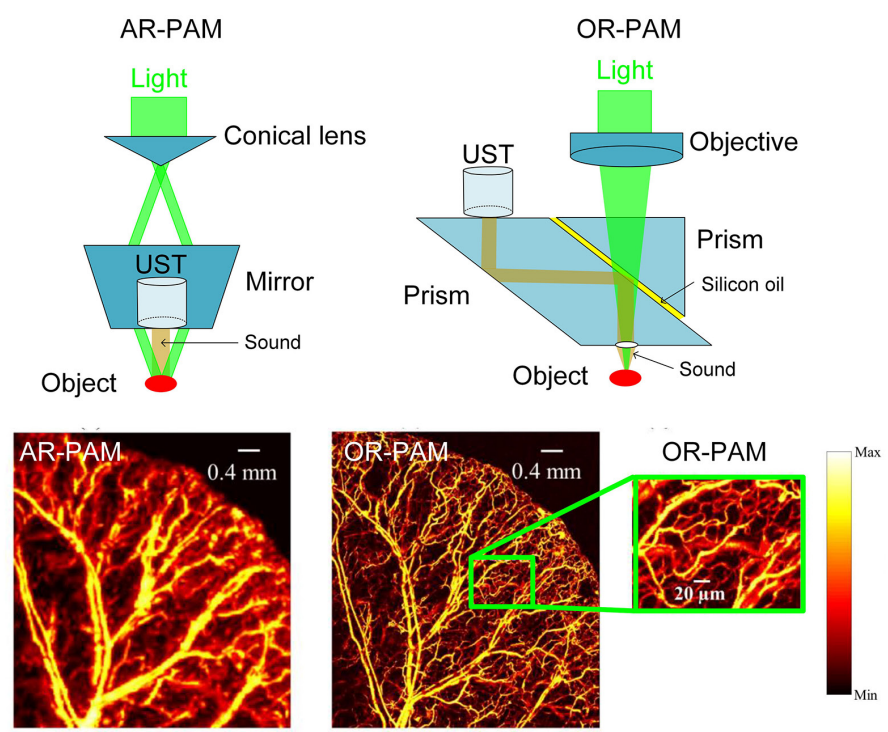

B
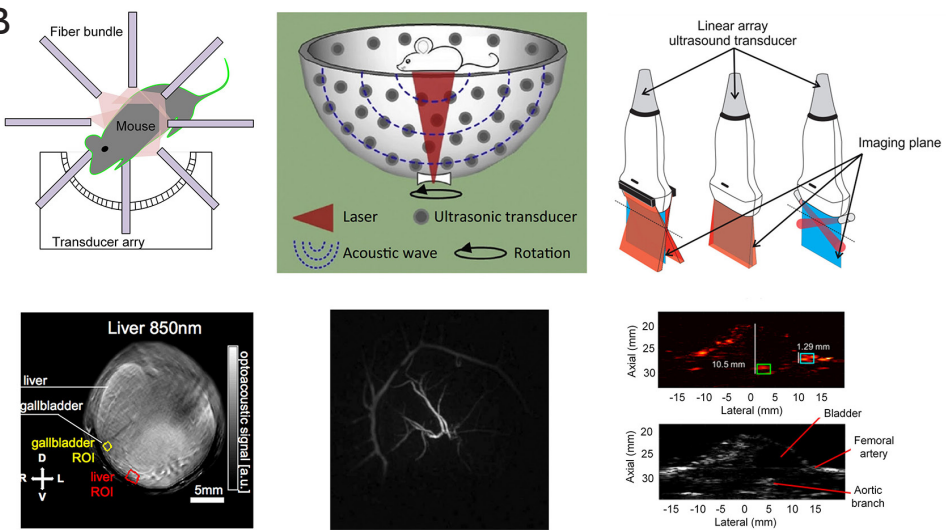

Figure 1 Schematic diagram of the device. (A) Schematic representation of AR-PAM system, OR-PAM system, and their photoacoustic images (39); (B) Three categories: circular, spherical, and planar geometry transducers of the PACT imaging system and their photoacoustic images (40-43). AR-PAM, acoustic-resolution photoacoustic microscopy; OR-PAM, optical-resolution photoacoustic microscopy; PACT, photoacoustic computed tomography.

half millimeter-scale resolution $(28,29)$. Therefore, PAM is capable of real-time single-organelle and single-cell imaging and is sensitive enough to capture subtle changes of disease microenvironments, including nutrition supplying capillaries, drug pharmacokinetics, and local acidity (30-32). There is a preference for PACT for macroscopic imaging such as organs, the whole-body, and so on $(33,34)$.

\section{Principle of PAM}

In PAM, both the optical excitation and ultrasound detection are focused, and the dual focuses are usually configured confocally to maximize sensitivity. Depending on whether the optical or US focus is finer, PAM is further classified into optical-resolution PAM (OR-PAM) and acoustic-resolution PAM (AR-PAM) (35-39). In OR-PAM, the optical focus is tighter than the acoustic focus, which provides the system optically defined lateral resolution. Owing to its high spatial resolution, OR-PAM has promoted technology advances to millisecond timescales and sub-micron length scales. In AR-PAM, the acoustic focus is smaller than the optical focus. Because the acoustically defined lateral resolution is not affected by optical scattering, AR-PAM could attain a deep imaging depth beyond the diffusion limit. Schematic representations of the AR-PAM system, OR-PAM system, and their photoacoustic images are exhibited in Figure $1 A$ (39). 


\section{Principle of PACT}

The PACT systems usually utilize a bright-field laser beam to illuminate a relatively large region of interest (ROI) (44). Photoacoustic signals are detected by unfocused or focused US transducers. Then, high resolution images can be reconstructed based on inverse algorithms such as back projection or time-reversed algorithms $(45,46)$. According to the anatomy of the target sample, commonly configured US transducers can be divided into three categories: circular $(47,48)$, spherical $(49)$, and planar geometry $(50)$. These transducers have been implemented for imaging in both smallanimals and humans (40-43), and are shown in Figure $1 B$.

Circular-array PACT is designed to accommodate around objects, such as the brain, a peripheral joint, and even a small animal's whole body. The ROI is encircled by the array to detect PA waves propagating along with all inplane directions, unlike partial-view detection in lineararray PACT. Full-view detection provides high-quality images without any boundaries being missed (40).

The hemispherical PAI system is an emerging, powerful, and non-invasive imaging mode in vivo. Owing to the unique bowl configuration, 128 flat transducers located on the surface of a bowl can collect photoacoustic signals from as many solid angles as possible. The 128 channel parallel data-acquisition system can acquire a volumetric image within $6 \mathrm{~s}$. Meanwhile, the laser's optical intensity is 1-2 orders of magnitude lower than the maximum permissible exposure, which guarantees its safety of use on living subjects $(41,42)$.

Planar array-based PACT can be implemented by taking advantage of commercial linear acoustic transducer arrays (43). Because of their cost-effectiveness, hand-held probes, and co-registered PA/US imaging characterization, the linear scanner arrays have been widely applied in PACT with much higher clinical availability than circular or spherical detectors.

\section{PAl of brain disease}

\section{Brain tumors}

Brain tumors have caused significant mortality throughout the world. Brain tumors may cause different symptoms depending on the location of diverse functional regions. Hence, the early diagnosis and effective therapy of brain tumors are of great significance for effective treatment. Owing to the brain's unique anatomical structure, surgical therapy is the predominant method of brain tumor therapy.
The completeness of surgical resection is a key factor in the prognosis of patients with brain tumors. However, the surgeon often encounters several challenges during the operation, including irregular and indistinct tumor margins and tumor growth adjacent to or invading crucial neurological structures. A wide variety of techniques have been investigated to visualize tumor margins better. For example, in preoperative MRI guided resection surgery, the MR images determine the tumor's macroscopic outline (51).

Moreover, intraoperative MRI usually requires the use of gadolinium, which has a short blood half-life; therefore, repeated injections and high dosages are often required that may result in inaccuracies (52). Brain tumor detection based on PAI breaks through these limits by taking advantage of diffusing photons and weak acoustic scattering (53). The device can be utilized to perform in vivo imaging before and during operation. Moreover, PAI can be used in the clinical diagnosis and treatment of brain tumors combined with other medical methods (54). For example, exogenous contrast agents like nanoparticles can be employed in vivo imaging for obvious and effective results (55). Also, PAI can be used together with other traditional medical methods, allowing for a more comprehensive brain tumor characterization. As shown in Figure 2, the tumor angiogenesis images (Figure $2 A$ ) were obtained by PACT after the injection of contrast agents (56). The shape and position of a brain tumor are shown in a photoacoustic image enhanced by nanoparticles' injection in Figure $2 B(57)$. Figure $2 C$ reveals the blood vessels $(532 \mathrm{~nm}$, red) and the nanoparticles accumulating in brain tumor tissue (680 $\mathrm{nm}$, green) in PA images captures after a tail vein injection of contrast agents (58). Figure $2 D$ shows an in vivo PAI of tumor-bearing mice at different time points following intravenous nanoparticle injection, which was monitored by the photoacoustic system (59). The photoacoustic images showed the contrast enhancement of nanoparticles in the tumor site. Before the injection of nanoparticles, a weak photoacoustic signal was observed in the tumor's upper skin region, which indicated an endogenous photoacoustic signal from hemoglobin in the blood vessels. Following the injection of nanoparticles, the photoacoustic signal at the tumor site increased over time. The photoacoustic signal at the injection site peaks at 4,12 , or $24 \mathrm{~h}$, depending on nanoparticles' property, which suggests highly efficient tumor retention and a sensitive photoacoustic contrast of nanoparticles.

Advances in mechanical engineering have allowed the integration of photoacoustic devices with other traditional 


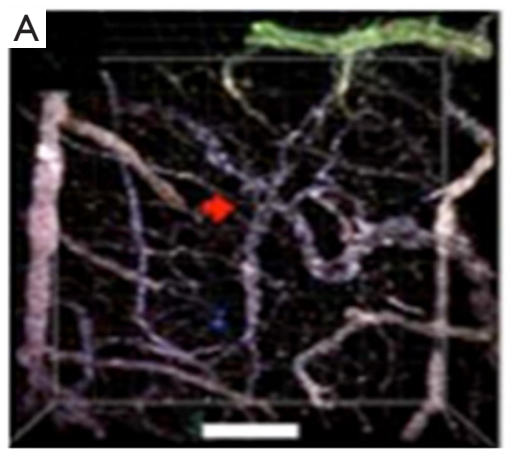

B

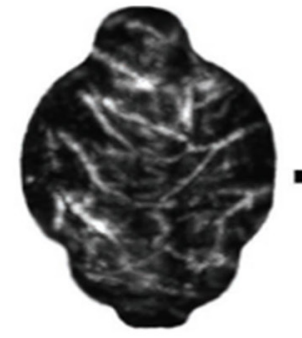

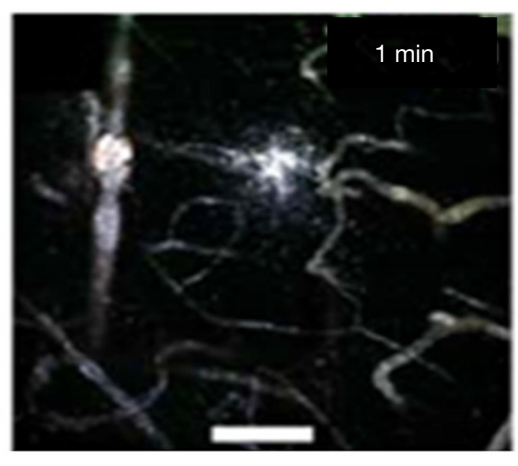

C
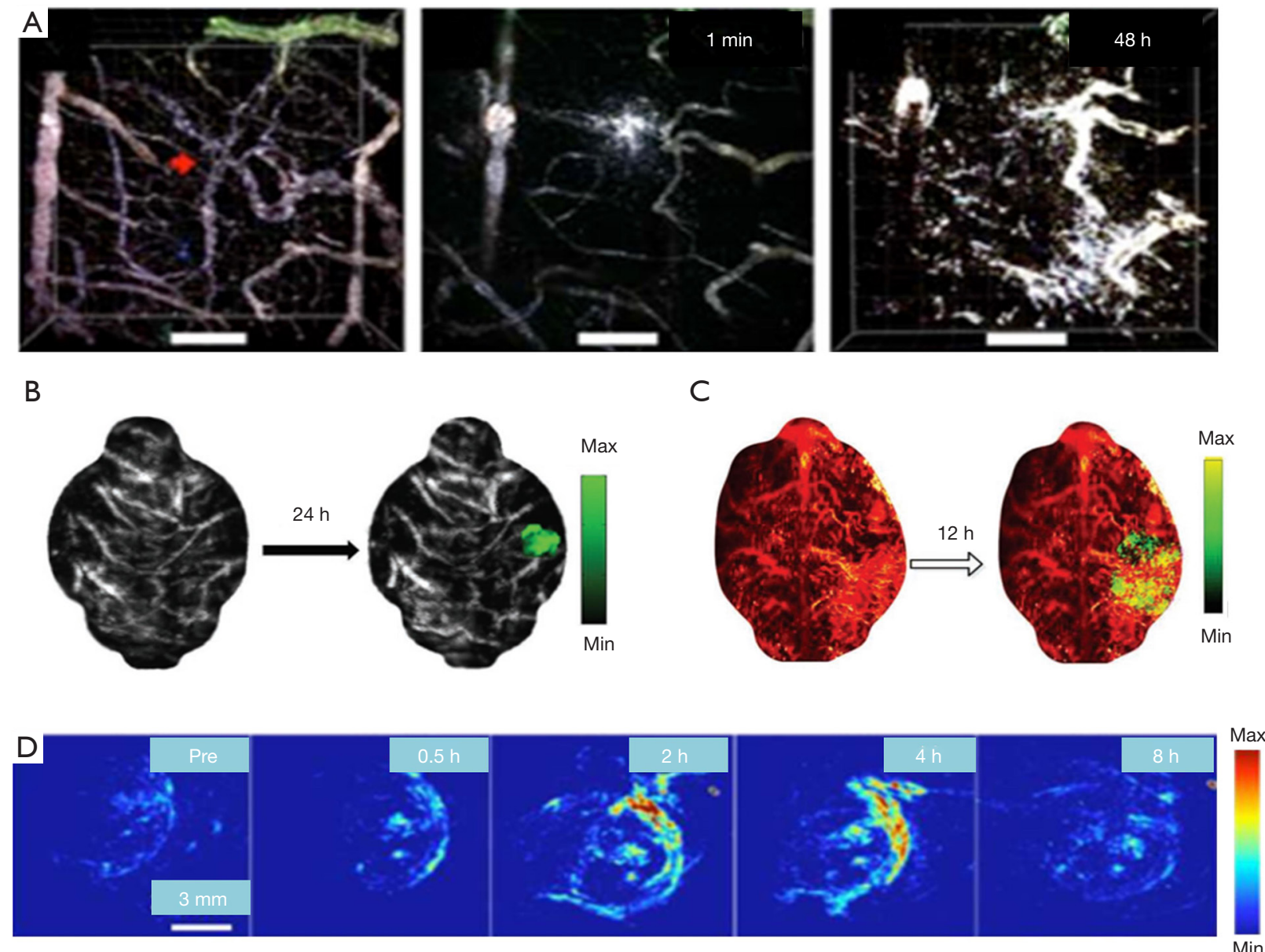

Figure 2 In vivo PAI of brain tumor. (A) PAI of tumor vessels prior to, $1 \mathrm{~min}$ after, and $48 \mathrm{~h}$ after laser irradiation. Red arrow denotes vascular tortuosity (56), Scale bar: $100 \mu \mathrm{m}$; (B) PAI of brain tumor region before, and after $24 \mathrm{~h}$, of injection of nanoparticles showing blood vessels (gray) and brain tumor (green tumor) (57); (C) Representative PAI of brain tumor region before, and $12 \mathrm{~h}$ after, tail vein injection of contrast agents showing blood vessels (532 nm, red) and the nanoparticles accumulate in the brain tumor tissue (680 nm, green) (58); (D) In vivo PAI of tumor-bearing mice at a different time points after intravenous injection of nanoparticles (59). PAI, photoacoustic imaging.

imaging methods. Kircher et al. developed a unique triple-modality MRI-PAI-Raman imaging nanoparticle (termed here MPR nanoparticles), that was detected by all three modalities, to accurately delineate the margins of brain tumors in living mice both preoperatively and intraoperatively (2). They injected MPRs in tumorbearing mice through the tail vein and performed PAI. After injecting MPRs into tumor-bearing mice, the tumor accumulates and retains nanoparticles, which accurately delineates the brain tumor margins. In addition to coupling with MRI, the PA technique can also complement US devices. With the help of exogenous contrast agents, the AR-PAM system collects the PA and US dual-modality images of the tumor's cross-section synchronously (Figure 3) (60). The US images show the skin and skull margins, and the PAI visualizes the tumor boundaries and confirms the tumor site.

\section{Epileptic seizure}

Epilepsy is the most common serious brain disorder, affecting $1 \%$ of the population worldwide (61). The population and shape of involved epileptic neurons vary along with the time and course of each epileptic event within a very short period (62). The imaging device's high temporal resolution facilitates finding the complete 

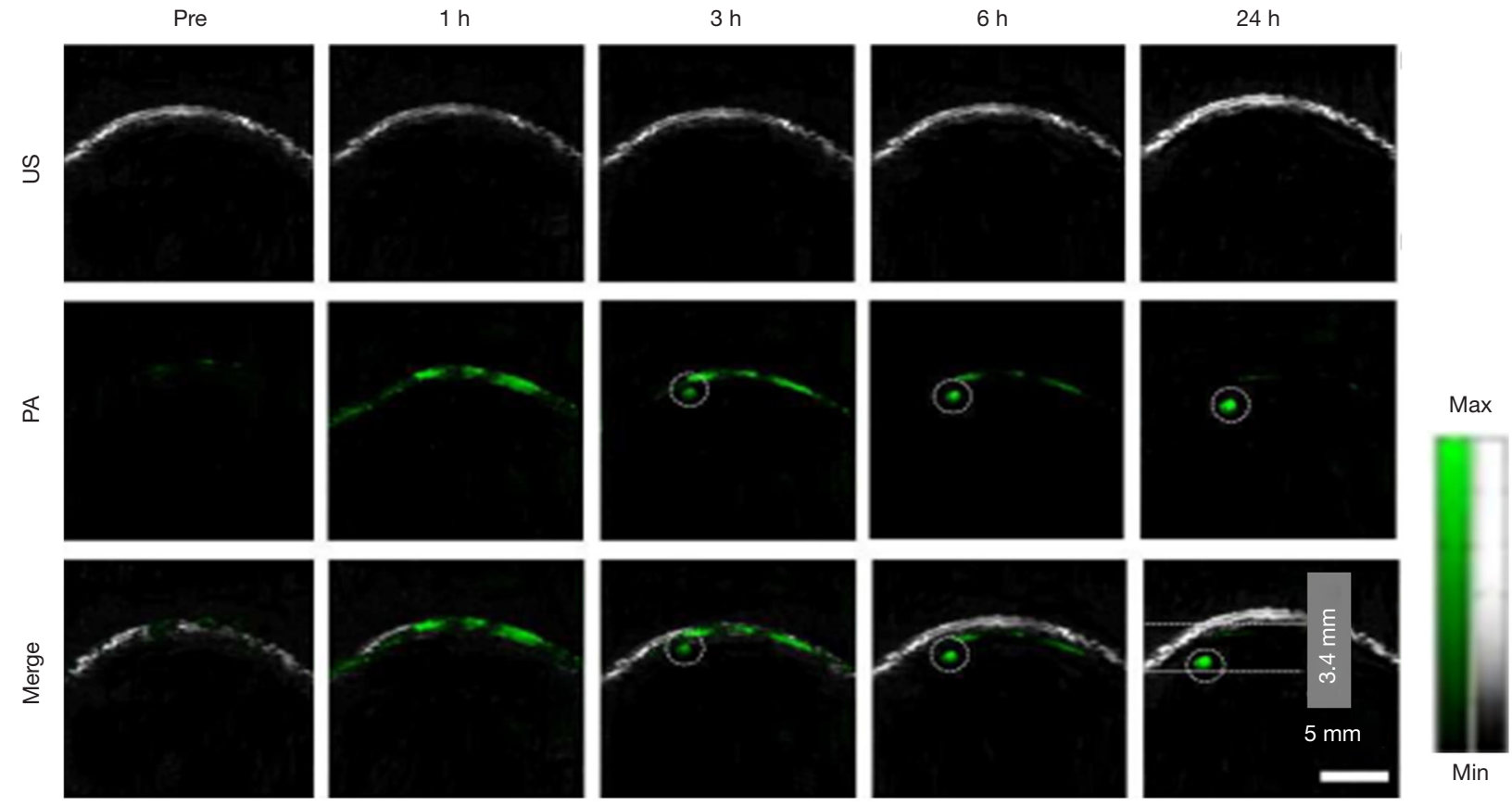

Figure 3 Multi-modality photoacoustic imaging of brain tumors. US images (grey) and B-scan photoacoustic images (green) of the brain tumor before and after nanoparticles injection (60). US, ultrasound.

mapping of epilepsy networks and the best opportunity for this is before and during epilepsy surgery. Current clinical, functional imaging methods, such as functional MRI, PET, and single-photon emission computed tomography (SPECT), are limited by their low temporal resolution in documenting such paroxysmal epileptiform events $(63,64)$. Since epileptic signal often appears for a very short time window, some patients with a subtle structural abnormality or functional abnormalities remain undetected with these imaging modalities, including MRI, PET, and SPECT. The PAM is an innovation in functional imaging that provides functional data such as the oxygen saturation of red blood cells in the microvasculature. Therefore, the PAM is a technology expected to have great utility in the diagnosis of epilepsy events. To the best of our knowledge, two forms of PA signals can be captured to detect epileptic seizures (65-71). The first is a PAI obtained by PAM (65-68), and the second is a PA signal curve captures by PA sensor technology (69-71).

A real-time three-dimensional (3D) PAI system was developed by Wang et al. for epilepsy imaging in small animals. It can record a complete set of $3 \mathrm{D}$ data, and the spatial resolution is about $0.2 \mathrm{~mm}$ (65). Also, phantom experiments were conducted to demonstrate the system's high imaging quality and real-time imaging ability. The induced seizure's focus area was successfully detected using this system on an acute epilepsy rat model: a set of PAI recovered from the data obtained at 6 time points after the bicuculline methiodide (BMI) injection (66). Another scientist observed a direct association of de-oxygenation at a wavelength of $755 \mathrm{~nm}$ with a significant optical absorption change (67); the area of focus increases in size over time, corresponding to an increase in the amplitude of the electroencephalography (EEG) spikes. Moreover, the PAM device captures the small blood vessels' vasodilatation caused by epileptic seizures (68).

On the other hand, PA sensor technology can detect the PA signal curve in epileptiform events. Hemodynamic changes are closely related to seizures. Accordingly, Wang et al. developed a portable device that integrates PA sensor technology with EEG to simultaneously record blood flow dynamics and total hemoglobin inside a single capillary (69). Changes in the PA signal present local field potential changes during BMI-induced localized and generalized seizure onsets. Our group has also explored the average PA signals of the superior sagittal sinus (SSS) and their comparison with the EEG signal (70). Herein, all the acquired results were following the results of EEG. 
Compared with other existing functional neuroimaging tools, the method proposed here enables reliable tracking of hemodynamic signals with both high spatial and high temporal resolution in $3 \mathrm{D}$, making it more suitable for the neurovascular coupling study of epilepsy.

\section{Acute brain injury}

Worldwide, acute brain injury is the leading cause of disability in people $<40$ years old, severely disabling 150-200 people per million each year (72-74). Brain injury may stretch, twist, tear nerve, blood vessels, and other brain tissues, resulting in damaged nerve pathways or causing bleeding and edema. Intracranial hemorrhage and brain edema increase the contents of the cranial cavity and intracranial pressure, which further destroys brain tissue. Increased intracranial pressure pushes the brain downward, forcing the upper brain tissue and brainstem into the associated foramen and causing a cerebral hernia. In cerebral hernia, the cerebellum and brainstem can be shifted from the foramen of the skull base to the spinal cord. Brain hernia is often fatal because the brain stem plays an important role in maintaining breathing and heartbeat $(75,76)$. Brain injury often leads to different degrees of permanent dysfunction, mainly depending on the inducement and location of brain injury, such as spinal cord injury (77), traumatic brain injury (TBI) (78), inflammatory injury (79), brain injury and rehabilitation (80), and stroke injury (81). Different brain damage regions can cause different symptoms, including motor, sensory, verbal, visual, auditory abnormalities, memory, and sleep disturbance (8284). Therefore, the brain injury location, vascular damage, and bleeding are very important for assessing the disease, the condition, and the expected treatment. It is meant to work towards detecting brain injury using the PAI technique on account of its nondestructive anatomical characteristics and function of high-contrast high-resolution imaging of hemoglobin.

Wu et al. have developed a PAI device with $1,730 \mathrm{~nm}$ excitation to assess white matter (WM) loss after a contusive spinal cord injury (SCI) in adult rats (77). Using this device in our current study, we were able to acquire B-scan PAI and the $3 \mathrm{D}$ PAI of normal spinal cord tissue and contusive injured tissue with or without treatment, suggesting that bond-selective PAI is a valuable tool to assess the progression of WM pathology after SCI as well as neuroprotective therapeutics in a label-free manner. Moreover, PAI can track the brain of mice with congestion and vascular damage caused by cortical damage, and the monitoring results are shown in Figure $4 A$ (78). A series of PA detection and reconstruction images (from day 1 to day 7) showed that the intensity of the PA signal of the brain injury hematoma and the extent of the blood clot section was gradually diminished and narrowed over time. By day 9, the intracerebral hematoma could hardly be displayed by PAI. On the 11th day following the injury, PAI found that congestion had disappeared, and cortex surface tissue was healed, and the previously destroyed cortical vessels could now be displayed. At this time, the anatomical section of the dissected mice's brains was consistent with the PAI. Most interestingly, scientists have explored the possibility of assessing resting-state functional connectivity using photoacoustic tomography (PAT) imaging in immature rat pups (79). In Figure 4B, locoregional cortical saturation $\left(\mathrm{SO}_{2}\right)$ showed a significant decrease in the LPS group compared to the $\mathrm{NaCl}$ group in the left cortex, which determines the impact of inflammation on the corpus callosum the cortex, both of which are known to be affected by inflammation.

Similarly, Li et al. employed fast PACT, with both skull and scalp intact, to monitor the mouse brain's damaged region and its recovery (80). As shown in Figure 4C, the damage location and the bleeding area's size change can be visualized at different time points. Both CT and MR images of the brain were acquired to confirm the injury. These findings showed that PACT enabled monitoring of the damaged vasculature with resulting hemorrhage and the rehabilitation process accompanied by the blood clot's resolution.

\section{Chemotherapy response}

There is no doubt that capturing subtle changes in the chemotherapy response is essential to assess tumor behavior, forecast the treatment response, adjust the therapy strategy if necessary, and maximize the therapeutic effect. Tumor vessel supply increases the transport of oxygen and other factors to cancer cells and expedites tumor growth and metastasis, which are the key criteria of disease aggression or inhibition $(85,86)$. The level of tumor neovascularization is a superb criterion to evaluate metastatic potential and monitor chemotherapy's response. Noninvasive imaging techniques are imperative for early cancer detection and prediction of chemotherapeutic efficacy on tumors. However, most standard imaging techniques like MRI, PET, and others provide only morphological tumor 

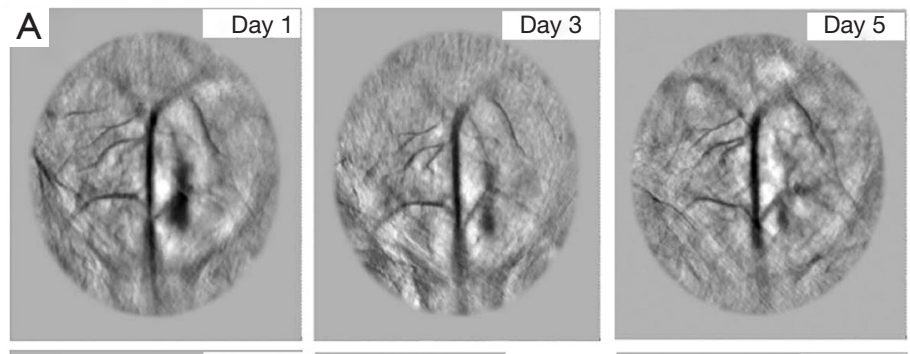

B
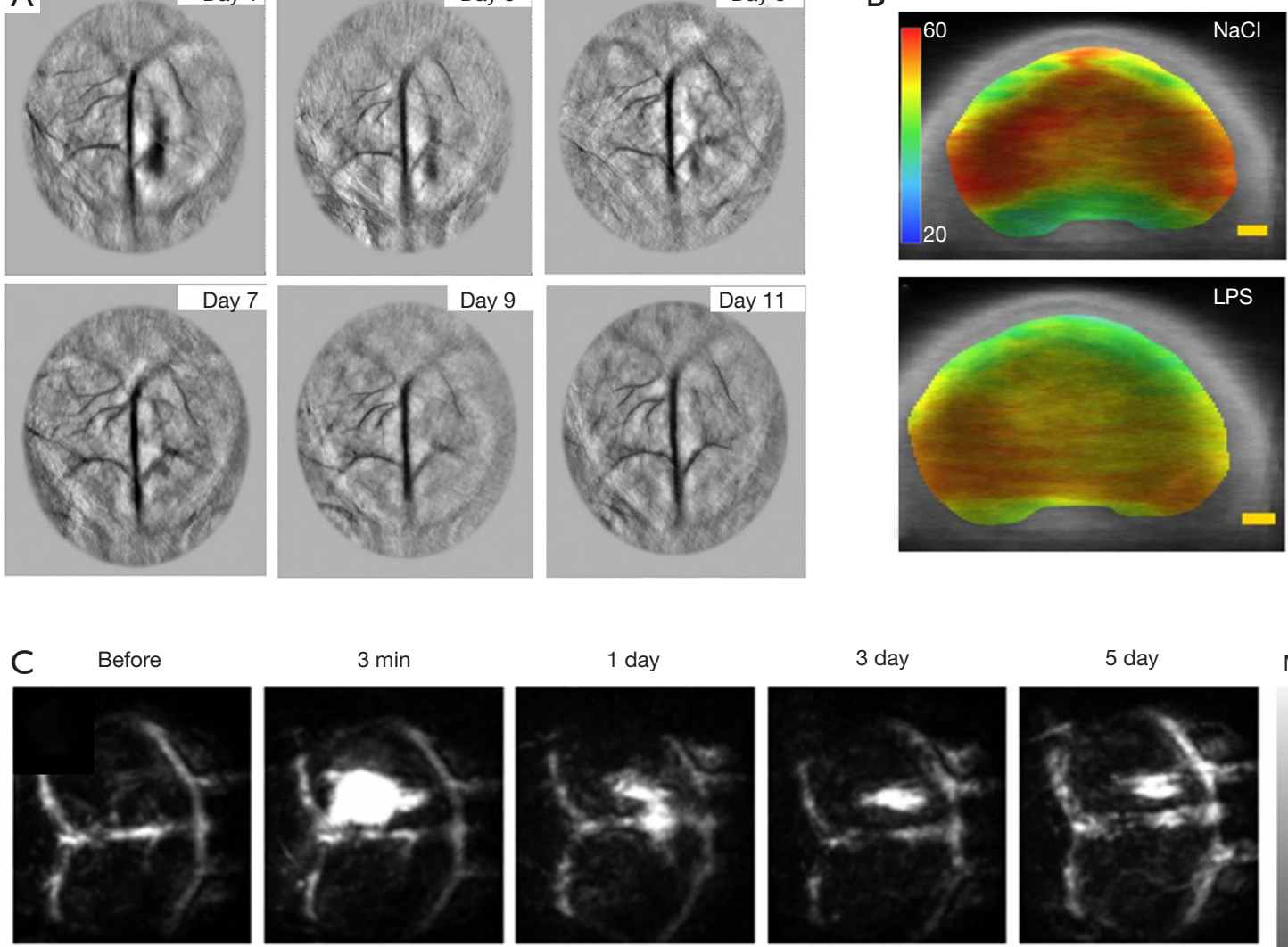

$\operatorname{Max}$
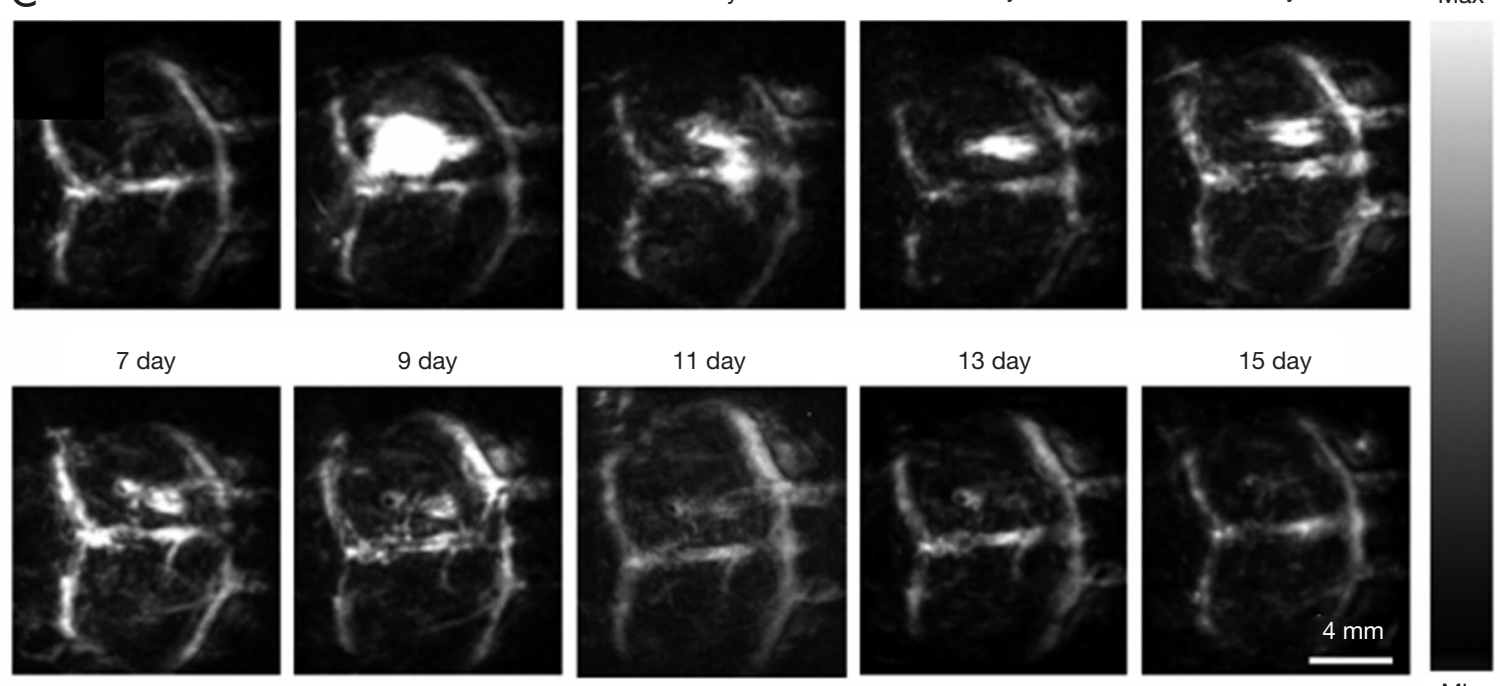

Figure 4 (A) Continuous monitoring imaging of the recovery process of photoacoustic brain injury (78); (B) Group averaged $\mathrm{SO}_{2}$ weighted PAI for $\mathrm{NaCl}$ (controls) and LPS group (79); (C) Photoacoustic images of the mouse brain at predetermined time intervals of injury after $3 \mathrm{~min}, 1,3,5,7,9,11,13$, and 15 days, respectively (80). PAI, photoacoustic imaging; LPS, lipopolysaccharide.

information such as density, size, and shape (87-89).

A sensitive and resolution-scalable PAM system with theranostic nanoformulation was developed to monitor the therapy response noninvasively promptly (Figure 5) (90). The PAI of the tumors receiving chemotherapy by the conventional PACT system and the PAM system is shown in Figure $5 A, B$. The former shows that the PA signal in the tumor region decreased slightly on day 8 . The latter results clearly show that the angiogenic vessels were greatly suppressed on day 4 , indicating the early-stage monitoring ability. The PAI system is capable of early-stage and sensitive detection of tumor angiogenesis. This prognosis method might potentially spare patients from suffering unnecessarily through an efficient chemotherapy course, switch to a new treatment course if necessary, and ultimately impact the survival rate. 
A
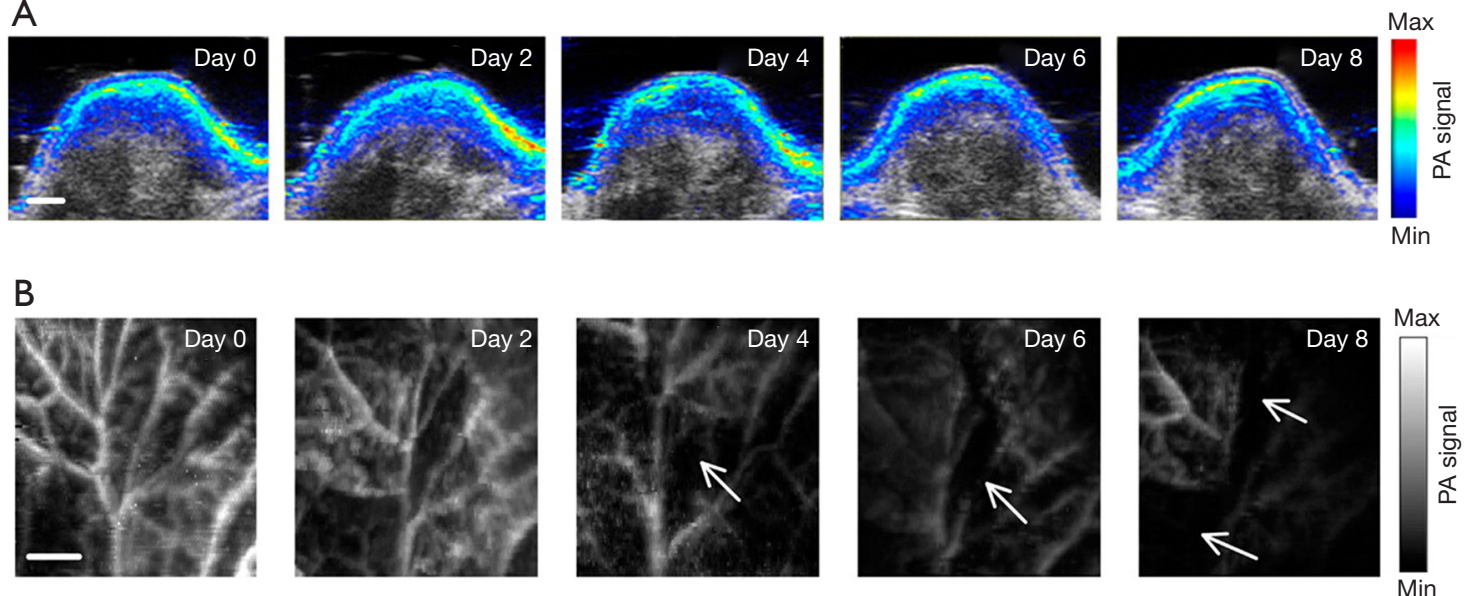

Figure $5 \mathrm{PAI}$ of the tumor receiving chemotherapy by the conventional PACT system (A) and the PAM system (B), Scale bar =1 mm (90). The arrows indicated the tumor vasculature of the tumor receiving chemotherapy. PAI, photoacoustic imaging; PAM, photoacoustic microscopy; PACT, photoacoustic computed tomography.

\section{Foreign body}

Foreign bodies are frequently encountered in medical imaging and range from intentionally placed objects, such as medical devices and surgical hardware, to debris from accidents and injuries and a wide variety of swallowed items. Various foreign bodies are well visualized with radiography, US, MRI, or other imaging modalities (91-94), and once detected, are often easily treated or even resolve spontaneously. Occasionally, however, foreign bodies go undetected and can have serious consequences. Untreated foreign bodies can cause various complications, including obstruction and perforation, nerve injury, chronic pain, abscesses, draining sinuses, and life-threatening infection (95). Delayed diagnosis can result in cellulitis and deep-tissue infections such as necrotizing fasciitis (96). Therefore, it is urgent to develop a noninvasive and feasible new imaging method based on the difference of optical absorption distribution for clinical detection of cerebral foreign bodies.

To demonstrate the PAI technique's ability to detect foreign bodies and traumatic lesions, a mouse brain cortex with two inserted small copper wires was imaged in vivo by our PAI system (76). Cortical vascular destruction and the abnormal display (black arrowhead, Figure $6 \mathrm{~A}$ ) indicated brain damage induced by the inserted metal wires. The reconstructed PAI provided the distribution of both the brain cortical vasculature and the inserted metal wires. To determine PAI accuracy, the mice with inserted wires were also subjected to digital X-ray imaging (Figure 6B).
Furthermore, a whole view of the cortical vessels, the skull, and the metal wires was displayed by a superposition image (Figure 6C) recombined from the $\mathrm{X}$-ray image and the PAI.

The modality PAI can be used for nondestructive imaging and localizing detection of foreign bodies in tissues and provides a noninvasive and feasible novel imaging method based on the difference of optical absorption distribution for clinical detection of brain foreign bodies. Further research may shed light on the current medical blind spot that low-density foreign bodies cannot be detected by X-ray.

\section{Brain plaque}

Cerebral amyloid angiopathy (CAA) occurs in most patients with Alzheimer's disease (AD) (97). The disorder that is $\mathrm{AD}$ is characterized by amyloid beta $(\mathrm{A} \beta)$ deposition in the walls of leptomeningeal arteries, cortical arteries, and veins in the brain (98). Considering that $\mathrm{A} \beta$ deposits can occur simultaneously or separately in both blood vessel walls and brain parenchyma (99), it is critical to developing a precise strategy to map the abnormality for further pinpointing CAA in vivo. However, the brain's grey and white matter are highly scattering and absorbing media and pose a great challenge for deep brain imaging (100); incident light is mainly attenuated by the cranium, which greatly limits the application of FLI for locating the plaque. Unlike FLI, PAI can ultrasonically break the strong optical scattering and simultaneously retain a high 

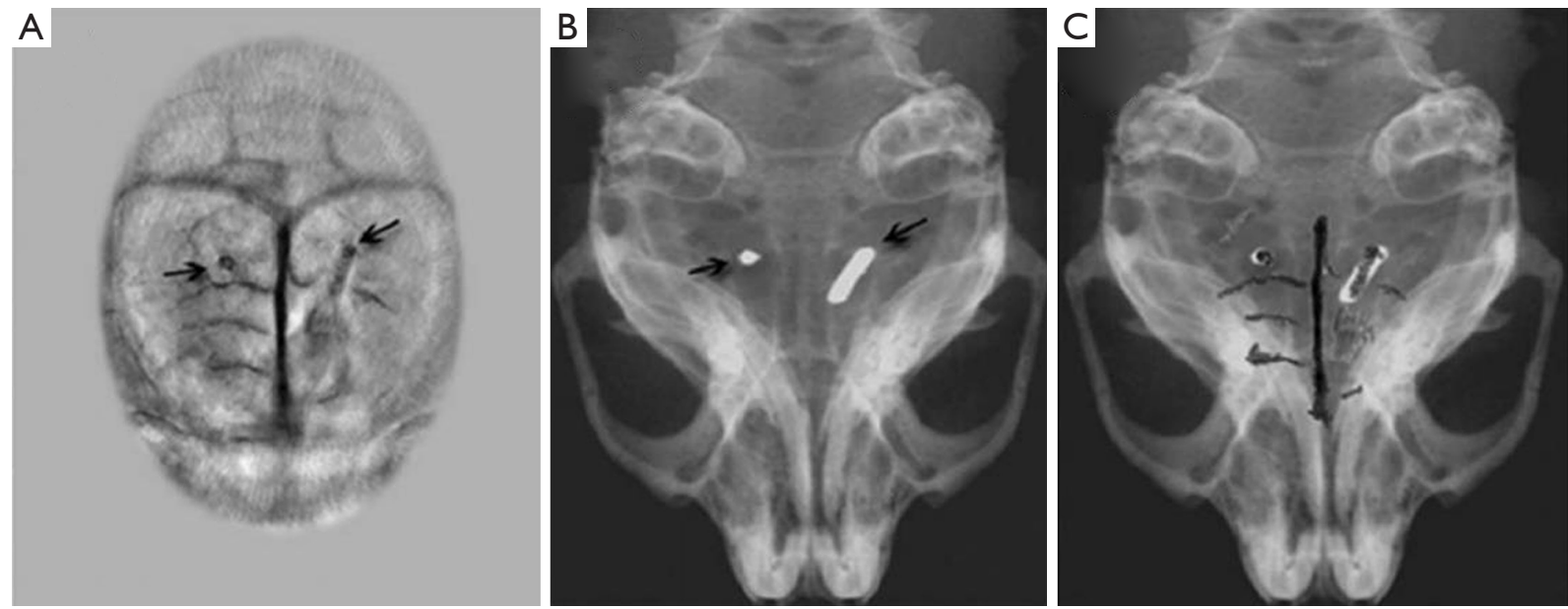

Figure 6 Metal foreign body detection in the brain by PAI. (A) photoacoustic image acquired with two small copper wires inserted in the mouse brain; (B) X-ray images corresponding to (A); (C) Recombined image with both (A) and (B) (78). The copper wires are identified by the arrows. PAI, photoacoustic imaging.

A

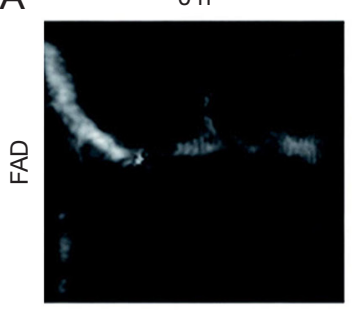

B

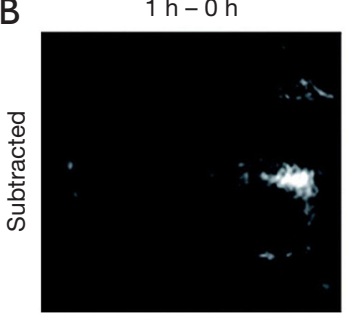

$1 \mathrm{~h}$

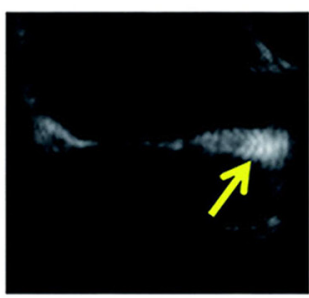

$4 h-0 h$

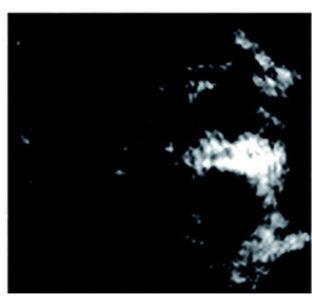

$4 \mathrm{~h}$

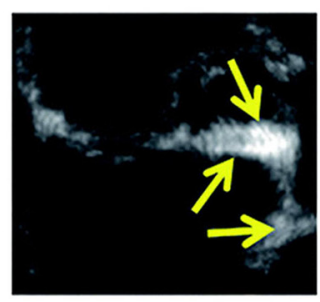

$8 \mathrm{~h}-0 \mathrm{~h}$

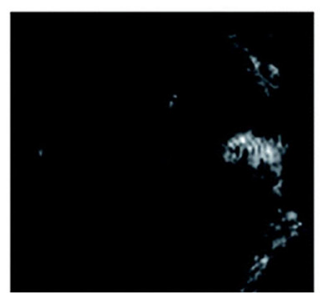

$8 \mathrm{~h}$

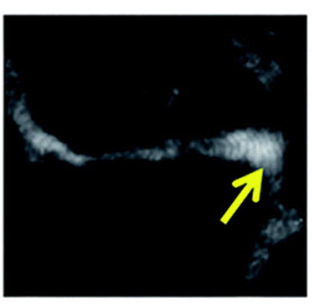

$4 h-8 h$

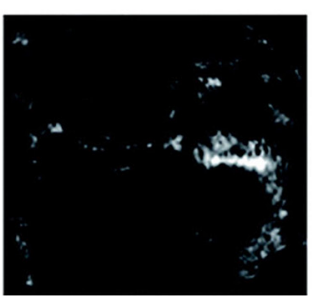

Figure $7 \mathrm{PAI}$ of brain plaque in mouse brain. (A) Photoacoustic maximum amplitude projection images recorded for Tg mice after an injection of contrast agents at different time points; the yellow arrows indicated the brain plaque in blood vessels of mouse. (B) Photoacoustic signal enhancement in mice brains of Tg (101). PAI, photoacoustic imaging;. Tg, transgenic.

penetration depth and spatial resolution.

For the first time, Li et al. have reported the evaluation of a specific PAI probe without antibody-labeling for A $\beta$ plaquetargeting imaging in a transgenic ( $\mathrm{Tg}$ ) mouse model (101). The PAI of the mice's brains is illustrated in Figure 7 at different time points after injection with the contrast agent. With the PAI results, the organic dye's PA signal displays an outstanding improvement in brain blood vessels in the Tg group, suggesting high $\mathrm{A} \beta$ fiber accumulation. We also performed differential PAI by subtracting the agent injection's raw PAIs from the PAIs at different time points to highlight the brain region further. As shown in Figure 7, significantly enhanced the PAI contrast of the sagittal sinus was observed by comparing the PA signals before and $4 \mathrm{~h}$ after injection. This may relate to brain plaque and the gradual accumulation of the dye in brain blood vessels. The PA signals of brain vessels from the $\mathrm{Tg}$ group decreased after $8 \mathrm{~h}$, which referred to small molecular dyes' 


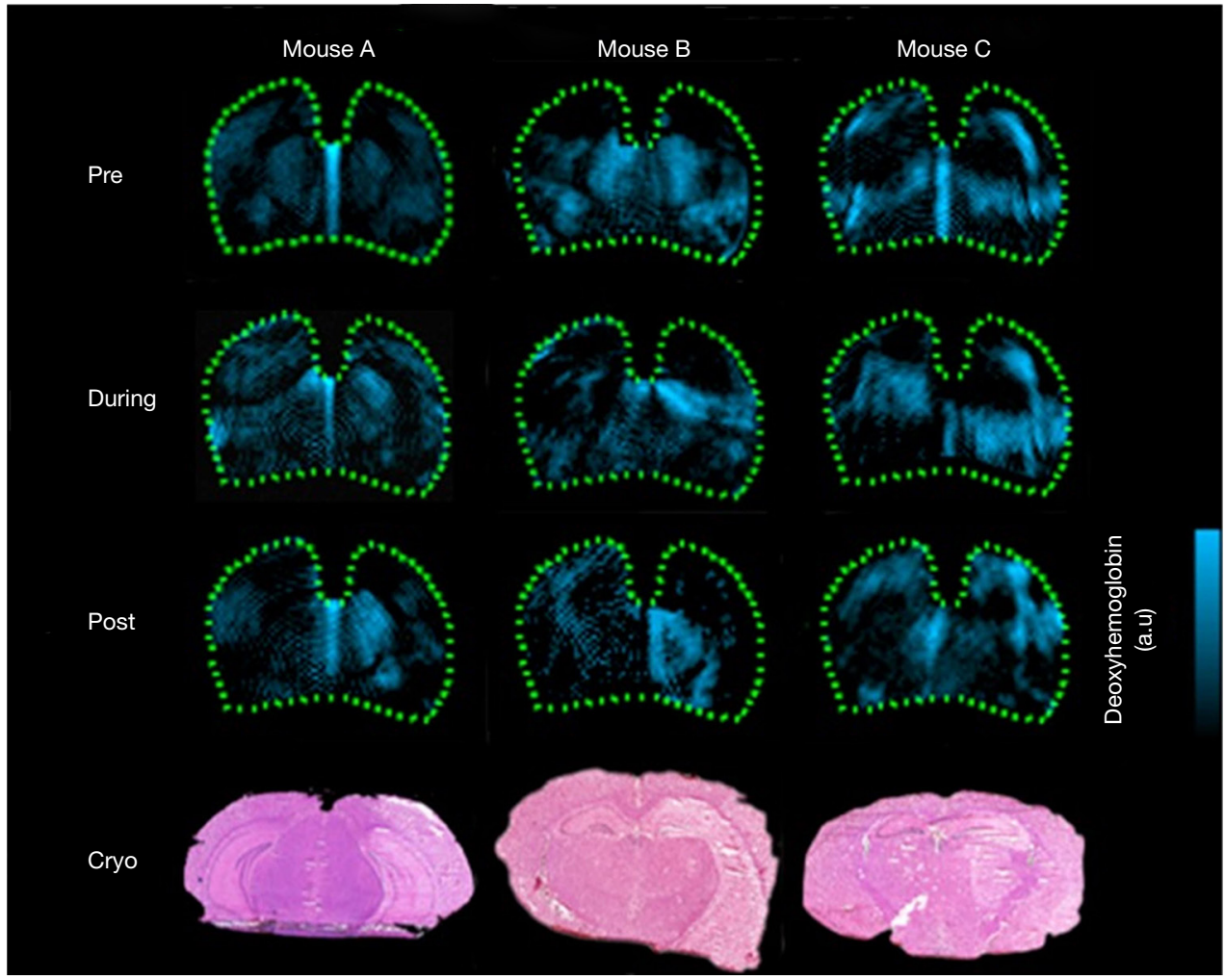

Figure 8 MSOT images for the brains of three MCAO mice (left to right) with corresponding HE stained cryosections for each mouse (bottom; per mouse). From top down: Pre-, during, and $24 \mathrm{~h}$ post-ischemia. Data for deoxygenated hemoglobin are presented in blue (108). MSOT, multispectral optoacoustic tomography; MCAO, middle cerebral artery occlusion; HE, hematoxylin and eosin.

metabolism. Our results demonstrated that PAI is capable of detecting brain plaque on cortical vessels.

\section{Brain stroke}

A stroke occurs when the blood supply to part of the brain is interrupted or reduced, preventing brain tissue from getting oxygen and nutrients. In the absence of oxygen and nutrients, brain cells necrotize in minutes. As a medical emergency, stroke can be devastating to individuals and their families. Stroke is the most common cause of adult disability, and over the past two decades, stroke has emerged as the second most common cause of death worldwide $(102,103)$. Therefore, early diagnosis and prompt treatment are crucial to reduce potential brain damage and other complications. It is essential to develop a long-term functional imaging method to monitor the progression of stroke. The sensitivity for hemoglobin and the non-invasive nature of PAI makes it possible to apply to brain imaging. Ovsepian et al. have developed the latest progress in photoacoustic neuroimaging (104-107). The use of PAI in stroke has also drawn the scientific community's attention $(108,109)$.

Kneipp et al. (108) investigated the applicability of realtime multispectral optoacoustic tomography (MSOT) for the monitoring of stroke progression following middle cerebral artery occlusion (MCAO) in the whole brain of live mice. As displayed in Figure 8, MSOT could monitor the deoxygenated hemoglobin distribution in several mice. Compared with the pre-ischemic stage, the images attained during, and $24 \mathrm{~h}$ post-ischemia show clear asymmetry in the vicinity of the infarcted regions that corresponded well with the histological sections. Histological findings further confirmed that the size of the hemoglobin asymmetry area and the associated signal strength, as revealed in the in vivo optoacsoustic scans, were closely related to the infarct. In this study, MSOT could detect an adjacent localized region with hemodynamic disturbance characteristics that reflect the ischemic penumbra. The unique capacity of MSOT to 
Table 2 Summary of the modality of PAI

\begin{tabular}{llll}
\hline Types & Modality & Disease Application & Ref \\
\hline Single-modality & PACT & Brain metabolism, tumor, epilepsy, chemotherapy response et al. & $(4,7,33,40,43,44,46,50,65-67,78)$ \\
& PAM & $\begin{array}{l}\text { Oxygen-metabolic, human lymphnodes, chemotherapy response, } \\
\text { myocardial infarction et al. }\end{array}$ & $39,8,9,31,32,32,53,79,37-$ \\
Multi-modality & PACT, MRI, Raman & Tumor & $(2)$ \\
& PACT, MRI, FL & Intracranial glioblastoma & $(54)$ \\
& PACT, MRI, CT & Tumor & $(59)$ \\
& PACT, OCT & Epilepsy & $(71)$ \\
& PACT, EEG & Epilepsy & $(68-70)$ \\
PACT, US & Lymph nodes & Brain Plaque & $(60)$ \\
& PAM, PET & (101)
\end{tabular}

PAI, photoacoustic imaging; PACT, photoacoustic computed tomography; PAM, photoacoustic microscopy; US, ultrasound; CT, computed tomography; MRI, magnetic resonance imaging; FL, fluorescence imaging; PET, positron emission tomography; OCT, optical coherence tomography; EEG, electroencephalogram.

monitor the hemoglobin level without introducing contrast agents demonstrates the further potential for use in the investigation of acute stroke. It may become a valuable and unique tool for functional stroke studies.

\section{Discussion and outlook}

Low temporal resolution, imperfect image contrast, ionizing radiation, high cost, and extended time requirements are the main limitations of conventional brain imaging techniques. The development of effective imaging approaches for the diagnosis of brain diseases is sought to circumvent these limitations. More innovative medical imaging approaches are required for brain imaging, mainly due to the brain's special anatomic structure and important physiological functions in the human body. As an innovative imaging modality, PAI has become a prevailing imaging technique by capitalizing on non-ionizing irradiation $(110,111)$. Based on thermoelastic expansion and acoustic wave propagation, PAI has a high spatial resolution of US imaging and deep penetration of optical imaging in biological tissues. Also, PA brain imaging has been greatly improved by customized and well-selected contrast agents.

This review introduced two mainstream PA devices that enable visualization from anatomical diseases to functional disorders. With PAM's powerful imaging capacity in microscopic biological structures and PACT in macroscopic structures, PAI has a wide range of preclinical applications in biology and medicine. This review also discussed and summarized PAM and PACT's preclinical application in brain disease diagnosis (Table 2). We conclude that PAI can be applied as a single-modality or integral part of a multimodality approach to diagnose brain diseases, including brain tumors, chemotherapy response, injury, foreign body, and brain plaques. The PAI can precisely capture subtle changes in the pathophysiological procedures of brain diseases such as behavior-related neurology, hemodynamic activities, localized seizure onsets, and white matter (WM) loss, which provides disease information at an early stage. Besides, specific PAI probes also promote PAI's specificity and efficiency; for instance, the tumor-targeted and $A \beta$ plaque targeted imaging.

While exciting breakthroughs have been achieved, the development of PAI in brain disease remains challenging. The research and development of key techniques in the PA device and the selection of contrast agents for deep brain imaging are two barriers that restrict PAI's further clinical translation. On the one hand, PAI in practical operation suffers from technical obstacles such as motion artifacts, inaccurate algorithms, and slow imaging speed. The precise design of PAI needs further improvement by instrument engineers. Additionally, PA systems are relatively bulky and cannot move freely.

Moreover, the current software operation technique is complicated and needs to be simplified into a user-friendly system. On the other hand, efficiency and biosafety should be concurrently taken into account when selecting contrast agents is conducted. So far, only a few contrast agents have been clinically approved. For example, the clinically 
approved iron oxide nanoparticles are not easily applied for deep-brain imaging due to weak absorption in the red or the near infrared reflectance (NIR) region. As for biosafety, the potential toxicity of contrast agents has not yet been fully elucidated. When used for a prolonged period, the rate of accumulation of contrast agents in the liver and spleen is also a very poorly understood area.

Nevertheless, there is still a long way to go before PAI can be widely applied in brain diseases' clinical diagnosis. Only clinical research on breast cancers and subcutaneous lymph nodes of humans by PAI has been reported $(112,113)$. In the future, the rapid development of nanotechnology and the promotion of PA devices will aid the advancement of photoacoustic molecular imaging, facilitate the preclinical investigation of biological processes in living subjects, and push the PAI modality towards clinical translation.

\section{Acknowledgments}

Funding: This work was supported by grants from the Natural Science Foundation of China (11704082, 51903062), Natural Science Foundation of Guangdong Province of China (2018A030313588), Guangdong Basic and Applied Basic Research Foundation (2020A1515011104, 2020A1515011320), and the Project of Educational Commission of the Guangdong Province of China (2017KQNCX163).

\section{Footnote}

Conflicts of Interest: All authors have completed the ICMJE uniform disclosure form (available at http://dx.doi. org/10.21037/qims-20-845). The authors have no conflicts of interest to declare.

Open Access Statement: This is an Open Access article distributed in accordance with the Creative Commons Attribution-NonCommercial-NoDerivs 4.0 International License (CC BY-NC-ND 4.0), which permits the noncommercial replication and distribution of the article with the strict proviso that no changes or edits are made and the original work is properly cited (including links to both the formal publication through the relevant DOI and the license). See: https://creativecommons.org/licenses/by-nc-nd/4.0/.

\section{References}

1. Wang LV, Gao L. Photoacoustic microscopy and computed tomography: From bench to bedside. Annu Rev Biomed Eng 2014;16:155-85.

2. Kircher MF, de la Zerda A, Jokerst JV, Zavaleta CL, Kempen PJ, Mittra E, Pitter K, Huang R, Campos C, Habte F, Sinclair R, Brennan CW, Mellinghoff IK, Holland EC, Gambhir SS. A brain tumor molecular imaging strategy using a new triple-modality MRIphotoacoustic-Raman nanoparticle. Nat Med 2012;18:829-34.

3. Wu D, Huang L, Jiang MS, Jiang H. Contrast agents for photoacoustic and thermoacoustic imaging: A review. Int J Mol Sci 2014;15:23616-39.

4. Bohndiek SE, Sasportas LS, Machtaler S, Jokerst JV, Hori S, Gambhir SS. Photoacoustic tomography detects early vessel regression and normalization during ovarian tumor response to the antiangiogenic therapy trebananib. J Nucl Med 2015;56:1942-47.

5. Luke GP, Emelianov SY. Optimization of in vivo spectroscopic photoacoustic imaging by smart optical wavelength selection. Opt Lett 2014;39:2214-17.

6. Yao J, Maslov KI, Zhang Y, Xia Y, Wang LV. Label-free oxygen-metabolic photoacoustic microscopy in vivo. J Biomed Opt 2011;16:076003.

7. Yao J, Xia J, Maslov KI, Nasiriavanaki M, Tsytsarev V, Demchenko AV, Wang LV. Noninvasive photoacoustic computed tomography of mouse brain metabolism in vivo. Neuroimage 2013;64:257-66.

8. Strohm EM, Berndl ES, Kolios MC. High frequency label-free photoacoustic microscopy of single cells. Photoacoustics 2013;1:49-53.

9. Guggenheim JA, Allen TJ, Plumb A, Zhang EZ, Rodriguez-Justo M, Punwani S, Beard PC. Photoacoustic imaging of human lymph nodes with endogenous lipid and hemoglobin contrast. J Biomed Opt 2015;20:50504.

10. Xu Z, Li C, Wang LV. Photoacoustic tomography of water in phantoms and tissue. J Biomed Opt 2010;15:036019.

11. Cao R, Kilroy JP, Ning B, Wang T, Hossack JA, Hu S. Multispectral photoacoustic microscopy based on an optical-acoustic objective. Photoacoustics 2015;3:55-9.

12. Cui C, Yang Z, Hu X, Wu J, Shou K, Ma H, Jian C, Zhao Y, Qi B, Hu X, Yu A, Fan Q. Organic semiconducting nanoparticles as efficient photoacoustic agents for lightening early thrombus and monitoring thrombolysis in living mice. ACS nano 2017;11:3298-310.

13. Karande GY, Hedgire SS, Sanchez Y, Baliyan V, Mishra V, Ganguli S, Prabhakar AM. Advanced imaging in acute and chronic deep vein thrombosis. Cardiovasc Diagn Ther 2016;6:493-507. 
14. Zhong J, Yang S. Contrast-enhanced photoacoustic imaging using indocyanine green-containing nanoparticles. J Innov Opt Health Sci 2014;7:1350029.

15. Chatni MR, Xia J, Sohn R, Maslov K, Guo Z, Zhang Y, Wang K, Xia Y, Anastasio M, Arbeit J, Wang LV. Tumor glucose metabolism imaged in vivo in small animals with whole-body photoacoustic computed tomography. J Biomed Opt 2012;17:076012.

16. Zhang Y, Jeon M, Rich LJ, Hong H, Geng J, Zhang Y, Shi S, Barnhart TE, Alexandridis P, Huizinga JD, Seshadri M, Cai W, Kim C, Lovell JF. Non-invasive multimodal functional imaging of the intestine with frozen micellar naphthalocyanines. Nat Nanotechnol 2014;9:631-8.

17. Tang Y, Hu H, Zhang MG, Song J, Nie L, Wang S, Niu G, Huang P, Lu G, Chen X. An aptamer-targeting photoresponsive drug delivery system using "off-on" graphene oxide wrapped mesoporous silica nanoparticles. Nanoscale 2015;7:6304-10.

18. Bai LY, Yang XQ, An J, Zhang L, Zhao K, Qin MY, Fang BY, Li C, Xuan Y, Zhang XS, Zhao YD, Ma ZY. Multifunctional magnetic-hollow gold nanospheres for bimodal cancer cell imaging and photothermal therapy. Nanotechnology 2015;26:315701.

19. Jin Y, Jia C, Huang S-W, O'donnell M, Gao X. Multifunctional nanoparticles as coupled contrast agents. Nat Commun 2010;1:41.

20. Lovell JF, Jin CS, Huynh E, Jin H, Kim C, Rubinstein JL, Chan WC, Cao W, Wang LV, Zheng G. Porphysome nanovesicles generated by porphyrin bilayers for use as multimodal biophotonic contrast agents. Nat Mater 2011;10:324-32.

21. Wilson K, Homan K, Emelianov S. Biomedical photoacoustics beyond thermal expansion using triggered nanodroplet vaporization for contrast-enhanced imaging. Nat Commun 2012;3:618.

22. Jathoul AP, Laufer J, Ogunlade O, Treeby B, Cox B, Zhang E, Johnson P, Pizzey AR, Philip B, Marafioti T, Lythgoe MF, Pedley RB, Pule MA, Beard P. Deep in vivo photoacoustic imaging of mammalian tissues using a tyrosinase-based genetic reporter. Nat Photonics 2015;9:239-46.

23. Razansky D, Distel M, Vinegoni C, Ma R, Perrimon N, Köster RW, Ntziachristos V. Multispectral opto-acoustic tomography of deep-seated fluorescent proteins in vivo. Nat Photonics 2009;3:412-7.

24. Yao J, Wang LV. Recent progress in photoacoustic molecular imaging. Curr Opin Chem Biol 2018;45:104-12.

25. Wang D, Wu Y, Xia J. Review on photoacoustic imaging of the brain using nanoprobes. Neurophotonics 2016;3:010901.

26. Li M, Tang Y, Yao J. Photoacoustic tomography of blood oxygenation: A mini review. Photoacoustics 2018;10:65-73.

27. Xia J, Yao J, Wang LV. Photoacoustic tomography: principles and advances. Electromagn Waves (Camb) 2014;147:1-22.

28. Wang LV, Hu S. Photoacoustic tomography: in vivo imaging from organelles to organs. Science 2012;335:1458-62.

29. Taruttis A, Ntziachristos V. Advances in real-time multispectral optoacoustic imaging and its applications. Nat photonics 2015;9:219.

30. Hu S, Wang LV. Optical-resolution photoacoustic microscopy: auscultation of biological systems at the cellular level. Biophys J 2013;105:841-7.

31. Zhang W, Ma HG, Cheng ZW, Wang ZY, Zhang L, Yang, SH. Miniaturized photoacoustic probe for in vivo imaging of subcutaneous microvessels within human skin. Quant Imaging Med Surg 2019;9:807-14.

32. Nie L, Cai X, Maslov KI, Garcia-Uribe A, Anastasio MA, Wang LV. Photoacoustic tomography through a whole adult human skull with a photon recycler. J Biomed Opt 2012;17:110506.

33. Li G, Li L, Zhu L, Xia J, Wang LV. Multiview Hilbert transformation for full-view photoacoustic computed tomography using a linear array. J Biomed Opt 2015;20:066010.

34. Hu S, Maslov K, Wang LV. Second-generation opticalresolution photoacoustic microscopy with improved sensitivity and speed. Opt Lett 2011;36:1134-6.

35. Maslov K, Zhang HF, Hu S, Wang LV. Optical-resolution photoacoustic microscopy for in vivo imaging of single capillaries. Opt lett 2008;33:929-31.

36. Zhang HF, Maslov K, Stoica G, Wang LV. Functional photoacoustic microscopy for high-resolution and noninvasive in vivo imaging. Nat Biotechnol 2006;24:848-51.

37. Favazza CP, Jassim O, Cornelius LA, Wang LV. In vivo photoacoustic microscopy of human cutaneous microvasculature and a nevus. J Biomed Opt 2011;16:016015.

38. Yao J, Wang L, Yang JM, Maslov KI, Wong TT, Li L, Huang CH, Zou J, Wang LV. High-speed label-free functional photoacoustic microscopy of mouse brain in action. Nat Methods 2015;12:407-10.

39. Moothanchery M, Pramanik M. Performance characterization of a switchable acoustic resolution and 
optical resolution photoacoustic microscopy system. Sensors 2017;17:357.

40. Taruttis A, Morscher S, Burton NC, Razansky D, Ntziachristos V. Fast multispectral optoacoustic tomography (MSOT) for dynamic imaging of pharmacokinetics and biodistribution in multiple organs. Plos One 2012; 7: e30491.

41. Nie L, Wang S, Wang X, Rong P, Ma Y, Liu G, Huang P, $\mathrm{Lu} G$, Chen X. In vivo volumetric photoacoustic molecular angiography and therapeutic monitoring with targeted plasmonic nanostars. Small 2014;10:1585-93.

42. Kruger RA, Lam RB, Reinecke DR, Del Rio SP, Doyle RP. Photoacoustic angiography of the breast. Med Phys 2010;37:6096-100.

43. Uliana JH, Sampaio DRT, Fernandes GSP, Brassesco MS, Nogueira-Barbosa MH, Carneiro AAO, Pavan TZ. Multiangle long-axis lateral illumination photoacoustic imaging using linear array transducer. Sensors 2020;20:4052.

44. Liu Y, Nie L, Chen X. Photoacoustic molecular imaging: from multiscale biomedical applications towards earlystage theranostics. Trends Biotechnol 2016;34:420-33.

45. Huang C, Nie L, Schoonover RW, Guo Z, Schirra CO, Anastasio MA, Wang LV. Aberration correction for transcranial photoacoustic tomography of primates employing adjunct image data. J Biomed Opt 2012;17:066016.

46. Huang C, Nie L, Schoonover RW, Wang LV, Anastasio MA. Photoacoustic computed tomography correcting for heterogeneity and attenuation. J Biomed Opt 2012;17:061211.

47. Razansky D, Buehler A, Ntziachristos V. Volumetric realtime multispectral optoacoustic tomography of biomarkers. Nat Protoc 2011;6:1121-9.

48. Burton NC, Patel M, Morscher S, Driessen WH, Claussen J, Beziere N, Jetzfellner T, Taruttis A, Razansky

D, Bednar B, Ntziachristos V. Multispectral opto-acoustic tomography (MSOT) of the brain and glioblastoma characterization. Neuroimage 2013;65:522-8.

49. Xia J, Wang LV. Small-animal whole-body photoacoustic tomography: a review. IEEE Trans Biomed Eng 2014;61:1380-9.

50. Gateau J, Caballero MÁA, Dima A, Ntziachristos V. Three-dimensional optoacoustic tomography using a conventional ultrasound linear detector array: Wholebody tomographic system for small animals. Med Phys 2013;40:013302.

51. Orringer DA, Chen T, Huang DL, Armstead WM,
Hoff BA, Koo YE, Keep RF, Philbert MA, Kopelman R, Sagher O. The brain tumor window model: A combined cranial window and implanted glioma model for evaluating intraoperative contrast agents. Neurosurgery 2010;66:736-43.

52. McDonald RJ, Levine D, Weinreb J, Kanal E, Davenport MS, Ellis JH, Jacobs PM, Lenkinski RE, Maravilla KR, Prince MR, Rowley HA, Tweedle MF, Kressel HY. Gadolinium Retention: A research roadmap from the 2018 NIH/ACR/RSNA workshop on gadolinium chelates. Radiology 2018;289:517-34.

53. Wang PH, Liu HL, Hsu PH, Lin CY, Wang CR, Chen PY, Wei KC, Yen TC, Li ML. Gold-nanorod contrastenhanced photoacoustic micro-imaging of focusedultrasound induced blood-brain-barrier opening in a rat model. J Biomed Opt 2012;17:061222.

54. Ni D, Zhang J, Bu W, Xing H, Han F, Xiao Q, Yao Z, Chen F, He Q, Liu J, Zhang S, Fan W, Zhou L, Peng W, Shi J. Dual-targeting upconversion nanoprobes across the blood-brain barrier for magnetic resonance/ fluorescence imaging of intracranial glioblastoma. Acs Nano 2014;8:1231-42.

55. Gao C, Deng ZJ, Peng D, Jin YS, Ma Y, Li YY, Zhu YK, Xi JZ, Tian J, Dai ZF, Li CH, Liang XL. Near-infrared dye-loaded magnetic nanoparticles as photoacoustic contrast agent for enhanced tumor imaging. Cancer Biol Med 2016;13:349-59.

56. Yuan H, Wilson CM, Xia J, Doyle SL, Li S, Fales AM, Liu Y, Ozaki E, Mulfaul K, Hanna G, Palmer GM, Wang LV, Grant GA, Vo-Dinh T. Plasmonics-enhanced and optically modulated delivery of gold nanostars into brain tumor. Nanoscale 2014;6:4078-82.

57. Chen JQ, Liu CB, Hu DH, Wang F, Wu HW, Gong XJ, Liu X, Song L, Sheng ZH, Zheng HR. Single Layer MoS2 Nanosheets with amplified photoacoustic effect for highly sensitive photoacoustic imaging of orthotopic brain tumors. Adv. Funct. Mater. 2016;26: 8715-25.

58. Liu L, Chen Q, Wen L, Li C, Qin H, Xing D. Photoacoustic therapy for precise eradication of glioblastoma with a tumor site blood-brain barrier permeability upregulating nanoparticle. Adv Funct Mater 2019;29:1808601.

59. Liu Y, Lv X, Liu H, Zhou Z, Huang J , Lei S, Cai S , Chen Z, Guo Y, Chen Z, Zhou X, Nie L. Porous gold nanocluster-decorated manganese monoxide nanocomposites for microenvironment-activatable MR/photoacoustic/CT tumor imaging. Nanoscale 2018;10:3631-8. 
60. Guo B, Sheng Z, Hu D, Liu C, Zheng H, Liu B. Biocompatible conjugated polymer nanoparticles for highly efficient photoacoustic imaging of orthotopic brain tumors in the second near-infrared window. Mater Horiz 2017;4:1151-6.

61. Glauser T, Ben-Menachem E, Bourgeois B, Cnaan A, Chadwick D, Guerreiro C, Kalviainen R, Mattson R, Perucca E, Tomson T. ILAE treatment guidelines: Evidence-based analysis of antiepileptic drug efficacy and effectiveness as initial monotherapy for epileptic seizures and syndromes. Epilepsia 2006;47:1094-120.

62. Fisher RS, Van Emde Boas W, Blume W, Elger C, Genton P, Lee P, Engel J Jr. Epileptic seizures and epilepsy: definitions proposed by the International League Against Epilepsy (ILAE) and the International Bureau for Epilepsy (IBE). Epilepsia 2005;46:470-2.

63. Devous MD Sr, Thisted RA, Morgan GF, Leroy RF, Rowe CC. SPECT brain imaging in epilepsy: a meta-analysis. J Nucl Med 1998;39:285-93.

64. Jackson GD, Connelly A, Cross JH, Gordon I, Gadian DG. Functional magnetic resonance imaging of focal seizures. Neurology 1994;44:850-6.

65. Wang B, Xiang L, Jiang MS, Yang J, Zhang Q, Carney PR, Jiang H. Photoacoustic tomography system for noninvasive real-time three-dimensional imaging of epilepsy. Biomed Opt Express 2012;3:1427-32.

66. Zhang Q, Liu Z, Carney PR, Yuan Z, Chen H, Roper SN, Jiang H. Non-invasive imaging of epileptic seizures in vivo using photoacoustic tomography. Phys Med Biol 2008;53:1921-31.

67. Xiang L, Ji L, Zhang T, Wang B, Yang J, Zhang Q, Jiang MS, Zhou J, Carney PR, Jiang H. Noninvasive real time tomographic imaging of epileptic foci and networks. Neuroimage 2013;66:240-8.

68. Tsytsarev V, Rao B, Maslov KI, Li L, Wang LV. Photoacoustic and optical coherence tomography of epilepsy with high temporal and spatial resolution and dual optical contrasts. J Neurosci Methods 2013;216:142-5.

69. Wang B, Zhou J, Carney P, Jiang H. A novel detachable head-mounted device for simultaneous EEG and photoacoustic monitoring of epilepsy in freely moving rats. Neurosci Res 2015;91:57-62.

70. Wang B, Xiao J, Jiang H. Simultaneous real-time 3D photoacoustic tomography and EEG for neurovascular coupling study in an animal model of epilepsy. J Neural Eng 2014;11:046013.

71. Xi L, Jin T, Zhou J, Carney P, Jiang H. Hybrid photoacoustic and electrophysiological recording of neurovascular communications in freely-moving rats. Neuroimage 2017;161:232-40.

72. Williams AM, Bhatti UF, Dennahy IS, Graham NJ, Nikolian VC, Chtraklin K, Chang P, Zhou J, Biesterveld BE, Eliason J, Alam HB. Traumatic brain injury may worsen clinical outcomes after prolonged partial resuscitative endovascular balloon occlusion of the aorta in severe hemorrhagic shock model. J Trauma Acute Care Surg 2019;86:415-23.

73. Agrawal D, Ahmed S, Khan S, Gupta D, Sinha S, Satyarthee GD. Outcome in 2068 patients of head injury: Experience at a level 1 trauma centre in India. Asian J Neurosurg 2016;11:143-5.

74. Feigin VL, Roth GA, Naghavi M, Parmar P, Krishnamurthi R, Chugh S, Mensah GA, Norrving B, Shiue I, Ng M, Estep K, Cercy K, Murray CJL, Forouzanfar MH. Global burden of stroke and risk factors in 188 countries, during 1990-2013: a systematic analysis for the Global Burden of Disease Study 2013. Lancet Neurol 2016;15:913-24.

75. Millis SR, Rosenthal M, Novack TA, Sherer M, Nick TG, Kreutzer JS, High WM Jr, Ricker JH. Long-term neuropsychological outcome after traumatic brain injury. J Head Trauma Rehabil 2001;16:343-55.

76. Cadena R, Shoykhet M, Ratcliff JJ. Emergency Neurological Life Support: Intracranial Hypertension and Herniation. Neurocrit Care 2017;27:82-8.

77. Wu W, Wang P, Cheng JX, Xu XM. Assessment of white matter loss using bond-selective photoacoustic imaging in a rat model of contusive spinal cord injury. J Neurotrauma 2014;31:1998-2002.

78. Yang S, Xing D, Lao Y, Yang D, Zeng L, Xiang L, Chen W. Noninvasive monitoring of traumatic brain injury and post-traumatic rehabilitation with laser-induced photoacoustic imaging. Appl Phys Lett 2007;90:243902.

79. Guevara E, Berti R, Londono I, Xie N, Bellec P, Lesage F, Lodygensky GA. Imaging of an inflammatory injury in the newborn rat brain with photoacoustic tomography. Plos One 2013;8:e83045.

80. Li W, Chen R, Lv J, Wang H, Liu Y, Peng Y, Qian Z, Fu G, Nie L. In vivo photoacoustic imaging of brain injury and rehabilitation by high-efficient near-infrared dye labeled mesen-chymal stem cells with enhanced brain barrier permeability. Adv Sci (Weinh) 2017;5:1700277.

81. Sakadžić S, Lee J, Boas DA, Ayata C. High-resolution in vivo optical imaging of stroke injury and repair. Brain Res 2015;1623:174-92.

82. Schanke AK, Sundet K. Comprehensive driving 
assessment: neuropsychological testing and on-road evaluation of brain injured patients. Scand J Psychol 2000; 41:113-21.

83. Lord C, Risi S, Lambrecht L, Cook EH Jr, Leventhal BL, DiLavore PC, Pickles A, Rutter M. The autism diagnostic observation schedule-generic: a standard measure of social and communication deficits associated with the spectrum of autism. J Autism Dev Disord 2000;30:205-23.

84. Ganau M, Iqbal M, Ligarotti GKI, Syrmos N. Breakthrough in the assessment of cerebral perfusion and vascular permeability after brain trauma through the adoption of dynamic indocyanine green-enhanced near-infrared spectroscopy. Quant Imaging Med Surg 2020;10:2081-4.

85. Hanahan D, Weinberg RA. Hallmarks of cancer: The next generation. Cell 2011;144:646-74.

86. Barinaga M. A face-off over tumor blood supply. Science 2000;287:783-5.

87. Fletcher BD, Hanna SL, Fairclough DL, Gronemeyer SA. Pediatric musculoskeletal tumors: use of dynamic, contrast-enhanced MR imaging to monitor response to chemotherapy. Radiology 1992;184:243-8.

88. Hoekstra CJ, Hoekstra OS, Stroobants SG, Vansteenkiste J, Nuyts J, Smit EF, Boers M, Twisk JW, Lammertsma AA. Methods to monitor response to chemotherapy in nonsmall cell lung cancer with $18 \mathrm{~F}-\mathrm{FDG}$ PET. J Nucl Med 2002;43:1304-9.

89. Straver ME, Aukema TS, Olmos RA, Rutgers EJ, Gilhuijs KG, Schot ME, Vogel WV, Peeters MJ. Feasibility of FDG PET/CT to monitor the response of axillary lymph node metastases to neoadjuvant chemotherapy in breast cancer patients. Eur J Nucl Med Mol Imaging 2010;37:1069-76.

90. Nie L, Huang P, Li W, Yan X, Jin A, Wang Z, Tang Y, Wang S, Zhang X, Niu G, Chen X. Early-stage imaging of nanocarrier-enhanced chemotherapy response in living subjects by scalable photoacoustic microscopy. Acs Nano 2014;8:12141-50.

91. Manson WC, Ryan JG, Ladner H, Gupta S. Comparison of metallic foreign-body removal between dynamic ultrasound and static radiography in a pigs' feet model. West J Emerg Med 2011;12:467-71.

92. Nishio Y, Hayashi N, Hamada H, Hirashima Y, Endo S. A case of delayed brain abscess due to a retained intracranial wooden foreign body: a case report and review of the last 20 years. Acta Neurochir (Wien) 2004;146:847-50.

93. Boutin RD, Briggs JE, Williamson MR. Injuries associated with MR imaging: survey of safety records and methods used to screen patients for metallic foreign bodies before imaging. AJR Am J Roentgenol 1994;162:189-94.

94. Kothbauer KF, Jallo GI, Siffert J, Jimenez E, Allen JC, Epstein FJ. Foreign body reaction to hemostatic materials mimicking recurrent brain tumor. Report of three cases. J Neurosurg 2001;95:503-6.

95. Pattamapaspong N, Srisuwan T, Sivasomboon C, Nasuto M, Suwannahoy P, Settakorn J, Kraisarin J, Guglielmi G. Accuracy of radiography, computed tomography and magnetic resonance imaging in diagnosing foreign bodies in the foot. Radiol Med 2013;118:303-10.

96. Yanay O, Vaughan DJ, Diab M, Brownstein D, Brogan TV. Retained wooden foreign body in a child's thigh complicated by severe necrotizing fasciitis: a case report and discussion of imaging modalities for early diagnosis. Pediatr Emerg Care 2001;17:354-5.

97. Gurol ME, Irizarry MC, Smith EE, Raju S, DiazArrastia R, Bottiglieri T, Rosand J, Growdon JH, Greenberg SM. Plasma $\beta$-amyloid and white matter lesions in AD, MCI, and cerebral amyloid angiopathy. Neurology 2006;66:23-9.

98. Weller RO, Massey A, Newman TA, Hutchings M, Kuo YM, Roher AE. Cerebral amyloid angiopathy: amyloid $\beta$ accumulates in putative interstitial fluid drainage pathways in Alzheimer's disease. Am J Pathol 1998;153:725-33.

99. Knobloch M, Konietzko U, Krebs DC, Nitsch RM. Intracellular $\mathrm{A} \beta$ and cognitive deficits precede $\beta$-amyloid deposition in transgenic arcA $\beta$ mice. Neurobiol Aging 2007;28:1297-306.

100. Gratton E, Fantini S, Franceschini MA, Gratton G, Fabiani M. Measurements of scattering and absorption changes in muscle and brain. Philos Trans R Soc Lond B Biol Sci 1997;352:727-35.

101.Liu Y, Yang Y, Sun M, Cui M, Fu Y, Lin Y, Li Z, Nie L. Highly specific noninvasive photoacoustic and positron emission tomography of brain plaque with functionalized croconium dye labeled by a radiotracer. Chem Sci 2017;8:2710-6.

102.Strong K, Mathers C, Bonita R. Preventing stroke: saving lives around the world. Lancet Neurol 2007;6:182-7.

103. Donnan GA, Fisher M, Macleod M, Davis SM. Stroke. Lancet 2008;371:1612-23.

104. Ovsepian SV, Olefir I, Westmeyer G, Razansky D, Ntziachristos V. Pushing the boundaries of neuroimaging with optoacoustics. Neuron. 2017;96:966-88.

105. Olefir I, Ghazaryan A, Yang H, Malekzadeh-Najafabadi J, Glasl S, Symvoulidis P, O'Leary VB, Sergiadis G, Ntziachristos V, Ovsepian SV. Spatial and spectral mapping and decomposition of neural dynamics and organization 
of the mouse brain with multispectral optoacoustic tomography. Cell Rep 2019;26:2833-46.e3.

106. Ovsepian SV, Olefir I, Ntziachristos V. Advances in optoacoustic neurotomography of animal models. Trends Biotechnol 2019;37:1315-26.

107. Ovsepian SV, Jiang Y, Sardella TCP, MalekzadehNajafabadi J, Burton NC, Yu X, Ntziachristos V. Visualizing cortical response to optogenetic stimulation and sensory inputs using multispectral handheld optoacoustic imaging. Photoacoustics 2019;17:100153.

108. Kneipp M, Turner J, Hambauer S, Krieg SM, Lehmberg J, Lindauer U, Razansky, D. Functional real-time optoacoustic imaging of middle cerebral artery occlusion in mice. Plos One 2014;9:e96118.

109.Lv J, Li S, Zhang J, Duan F, Wu Z, Chen R, Chen MM, Huang SS, Ma, HS, Nie LM. In vivo photoacoustic imaging dynamically monitors the structural and functional changes of ischemic stroke at a very early stage. Theranostics 2020;10:816-28.

Cite this article as: Qiu T, Lan Y, Gao W, Zhou M, Liu S, Huang W, Zeng S, Pathak JL, Yang B, Zhang J. Photoacoustic imaging as a highly efficient and precise imaging strategy for the evaluation of brain diseases. Quant Imaging Med Surg 2021;11(5):2169-2186. doi: 10.21037/qims-20-845
110. Wang Y, Zhan Y, Harris LM, Khan S, Xia J. A portable three-dimensional photoacoustic tomography system for imaging of chronic foot ulcers. Quant Imaging Med Surg 2019;9:799-806.

111. Yang J, Zhang G, Li Q, Liao C, Huang L, Ke T, Jiang H, Han D. Photoacoustic imaging for the evaluation of early tumor response to antivascular treatment. Quant Imaging Med Surg 2019;9:160-70.

112.Dogan BE, Menezes GLG, Butler RS, Neuschler EI, Aitchison R, Lavin PT, Tucker FL, Grobmyer SR, Otto PM, Stavros AT. Optoacoustic imaging and gray-scale US features of breast cancers: Correlation with molecular subtypes. Radiology 2019;292:564-72.

113. Suzuki Y, Kajita H, Konishi N, Oh A, Urano M, Watanabe S, Asao Y, Imanishi N, Tsuji T, Jinzaki M, Aiso S, Kishi K. Subcutaneous lymphatic vessels in the lower extremities: Comparison between photoacoustic lymphangiography and near-infrared fluorescence lymphangiography. Radiology 2020;295:469-74. 